\title{
INFLUENCE OF ALUMINIUM AND AUTOCLAVING TEMPERATURE ON THE PROPERTIES OF AUTOCLAVED AERATED CONCRETE
}

\author{
Mohei Menul Islam*, Muhammad Harunur Rashid, and Md. Aqib Muntasir \\ Department of Civil Engineering, Khulna University of Engineering \& Technology, Bangladesh \\ Received: 06 May 2021 \\ Accepted: 24 August 2021
}

\begin{abstract}
Autoclaved aerated concrete (AAC) prepared by the mixing of ordinary Portland cement, lime powder, sand, aluminium powder and water. This study covers the variation of physical, mechanical and functional properties of autoclaved aerated concrete with autoclaving temperature and aluminium content and compared with that of normal weight cement mortar sample. In this work, two dosage of aluminium content of $0.4 \%$ and $0.8 \%$ of the dry weight of ordinary Portland cement and three different autoclaving temperature of $160^{\circ} \mathrm{C}, 180^{\circ} \mathrm{C}$ and $200^{\circ} \mathrm{C}$ were used. AAC sample with $0.8 \%$ aluminium and $160^{\circ} \mathrm{C}$ temperature had unit weight of $1490 \mathrm{~kg} / \mathrm{m}^{3}$ which was lowest among all samples including the control or normal weight cement blocks. Weight reduction of AAC sample was $31.53 \%$. AAC sample with $0.4 \%$ aluminium and $200^{\circ} \mathrm{C}$ autoclaving temperature gave maximum compressive and tensile strength of $19.4 \mathrm{MPa}$ and $1.81 \mathrm{MPa}$ respectively which were close to that of normal weight concrete and strength of AAC increased with autoclaving temperature and decreased with aluminium content. In this research, the functional propertiesof AAC, absorption capacity was much higher than normal weight concrete and this capacity was increased with aluminium content and with decreasing autoclaving temperature and unit weight of AAC. For AAC with $0.8 \%$ aluminium and $160^{\circ} \mathrm{C}$ temperature gave maximum water absorption capacity (=9.93\%). Again, surface absorption rate was higher for first 12 hours and with time it would be constant because of its saturated position.
\end{abstract}

Keywords: Autoclaved aerated concrete, Autoclaving temperature, Aluminium, Functional properties, Mechanical properties.

\section{INTRODUCTION}

Autoclaved aerated concrete is a structural material which is generated by mixing of ordinary Portland cement, fine aggregate, lime powder, aluminium powder with small amount and water and by the steam curing in autoclaved at constant high autoclaving temperature and pressure. AAC is actually a light-weight concrete which is commonly used around the world specially in Asia and Europe, particularly as it combines ease of construction with excellent combination of mechanical and thermal properties (Narayanan \& Ramamurthy, 2000). Autoclaved aerated concrete, an environmentally friendly material may have considerable potential for further applications (Robert et al., 2013). Before use AAC, it should be known about its various physical, mechanical and functional properties. Physical properties are shape, size, microstructure, dry unit weight, moist unit weight etc. Mechanical properties are compressive, tensile, flexural strength, modulus of elasticity, shrinkage, creep etc. Functional properties are water and surface absorption capacity, fire resisting capacity etc.

Autoclaved aerated concrete (AAC) gains its light-weight property by a mechanism that consist of a chemical reaction between $\mathrm{Ca}(\mathrm{OH})_{2}$ and aluminium powder $(\mathrm{Al})$. Through this reaction, hydrogen gas $\left(\mathrm{H}_{2}\right)$ is produced that makes pores in the AAC. For that reason, AAC is porous and has less self-weight than normal weight concrete. The chemical reaction is (Holt \& Raivio, 2005) :

$$
2 \mathrm{Al}+3 \mathrm{Ca}(\mathrm{OH})_{2}+6 \mathrm{H}_{2} \mathrm{O}=3 \mathrm{CaO} \cdot \mathrm{Al}_{2} \mathrm{O}_{3} \cdot 6 \mathrm{H}_{2} \mathrm{O}+3 \mathrm{H}_{2} \text { (gas) }
$$

Autoclaved aerated concrete is prepared by steam cured at autoclaved at high temperature and pressure. This temperature and pressure vary from $180^{\circ} \mathrm{C}$ to $210^{\circ} \mathrm{C}$ and 4 to $16 \mathrm{MPa}$. The curing period is within $8 \mathrm{~h}$ to $18 \mathrm{~h}$ continuously. This steam curing of AAC is performed at constant temperature, pressure and curing period (Hauser et al., 1999).

The unit weight of AAC can be in the range of 400 to $800 \mathrm{~kg} / \mathrm{m}^{3}$ and has less thermal conductivity than normal weight concrete $(0.16-0.18 \mathrm{~W} / \mathrm{m}-\mathrm{k})$ (Anon, 1970). For light-weight (aerated) concrete this bulk density varies from 300 to $1850 \mathrm{~kg} / \mathrm{m}^{3}$ (Neville, 2011). 
Robert et al., (2013) studied about hygric, thermal properties of AAC with unit weight and compressive strength of AAC and also discusses about durability and various physical properties of AAC. Tanaçan et al., (2009) investigated the effect of increased temperature and different cooling regime on behaviour of aerated concrete. Tanaçan et al., (2005) investigated for the cellular gas concrete, impact on various mechanical properties and velocity of ultrasound due to elevated temperature. They applied temperature with the range of $100^{\circ} \mathrm{C}$ to $965^{\circ} \mathrm{C}$. Kumar \& Ramamurthy (2015) showed impact on various properties of aerated concrete with moist-cured due to various aluminium content and its fineness. Sanjayan et al. (2015) investigated effect of various aluminium content on different properties of geopolymer aerated concrete.

As other physical properties of AAC are related with the unit weight $\left(1800 \pm 300 \mathrm{~kg} / \mathrm{m}^{3}\right)$. For the calculation, the moisture condition is needed to be indicated. The unit weight of autoclaved aerated concrete cured from autoclaved immediately is $15 \pm 25 \%$ up to $45 \%$ heavier than the oven-dried AAC concrete (Narayanan \& Ramamurthy, 2000). The density of aerated concrete decreases with the fineness of aluminium powder for a specific dosage of it. High w/c ratio (0.4 to 0.6$)$ gives more weight reduction $(30 \%$ to $35 \%)$ of aerated concrete when the aluminium content is in the range of 0.25 to $0.50 \%$ of the weight of binding material respectively. Dry density and compressive strength decreases with aluminium content and water absorption capacity increases with aluminium content (Kumar \& Ramamurthy, 2015).

The range of moisture content of autoclaved aerated concrete (AAC) is termed as water absorption of AAC. The capacity of water absorption varies with different dosage of aluminium powder (Koronthalyova, 2011). The overall surface absorption is explained as the combination of two processes: a surface absorption through aerated pores of AAC that quickly gains gravitational equilibrium and surface absorption with slow rate through the matrix pores that follows the criterion $\mathrm{t}^{1 / 2}$ law. The capillary or surface absorption of AAC may be presented by three parameters, such as: the capillarity of matrix, the capillarity of aerated pores and the aeration pore capillary rise cumulative absorption (Ioannou et al., 2008).

In this research work, effect of various autoclaving temperature and aluminium powder content on various physical, mechanical and functional properties of AAC has been investigated and compared these properties with that of normal weight concrete or control block.

\section{METHODOLOGY}

\subsection{Materials for samples}

The materials used in this research were OPC, sand with 1.25FM, 20\% lime powder of OPC, aluminium powder of $0.4 \%$ and $0.8 \%$ of total dry weight of OPC. These materials' pastes were prepared by hand mix with sufficient water according to $\mathrm{w} / \mathrm{c}$ ratio of 0.5 to make the mixture with suitable workability and homogeneity. Table 1 is given to show the sieve analysis of sand with $1.25 \mathrm{FM}$ and properties of this sand respectively.

Table 1: Properties of sand

\begin{tabular}{|c|c|c|c|c|c|}
\hline \multirow[t]{2}{*}{ FM of sand } & \multicolumn{2}{|c|}{ Unit weight $\left(\mathrm{kg} / \mathrm{m}^{3}\right)$} & \multicolumn{2}{|c|}{ Specific gravity } & \multirow{2}{*}{$\begin{array}{l}\text { Water absorption capacity } \\
(\%)\end{array}$} \\
\hline & $\begin{array}{c}\text { Loose } \\
\text { condition }\end{array}$ & $\begin{array}{l}\text { Compact } \\
\text { condition }\end{array}$ & Oven dry & SSD & \\
\hline 1.25 & 1487 & 1612 & 2.35 & 2.43 & 3.65 \\
\hline
\end{tabular}

\subsection{Experimental program}

\subsubsection{Kneading and readiness of sample}

The experimental samples were prepared according to ASTM C109. Mix proportion of AAC by weight of OPC cement: sand: lime: aluminium powder was $1: 2.2: 0.2: 0.004$ and 1:2.2:0.2:0.008. W/c ratio was 0.5 for both mix proportion of AAC.

All the ingredients without aluminium powder were mixed by hand for 3 minutes so that the mixture becomes homogeneous and with uniform colour. Then aluminium powder with desired amount was added to that composition and compounded thoroughly about $30 \mathrm{sec}$. After that required amount water was added to the mixture to make homogeneous paste. According to ASTM C109 standard, that paste was poured in the moulds and tamped the paste by a tamping bar. The surface of the paste was levelled with the straight edge and this levelling process was continued to 120 minutes due to volume increasing of that paste. Then the moulds with paste were kept in the room at room temperature and 75\% relative humidity according to Un \& Baradan, 2011. 
By this process 36 numbers of $50 \times 50 \times 50 \mathrm{~mm}$ blocks and 9 numbers of briquettes with standard size were prepared for each sample type.

Conventional or normal weight concrete blocks and briquettes with same amount and size stated above were prepared with same amount of ingredients without adding lime and aluminium powder.

\subsubsection{Steam curing of AAC (Autoclaving process)}

After 24 hours from casting the samples were demoulded and then kept in the autoclave chamber. These blocks were cured in the autoclave for $8 \mathrm{~h}$ continuously at constant high temperature $160^{\circ} \mathrm{C}, 180^{\circ} \mathrm{C}$ and $200^{\circ} \mathrm{C}$ separately and $8 \mathrm{~atm}$ pressure with each temperature. Each sample type was introduced to autoclaving processes at three different temperatures and each time temperature and pressure were constant through the curing period. 36 numbers of blocks and 9 numbers of briquettes with standard size were autoclaved together with desired time.

After autoclaving, the samples were cooled and stored in the laboratory at room temperature and $75 \%$ relative humidity.

\subsubsection{Physical properties}

\subsubsection{Unit weight}

The three $50 \times 50 \times 50 \mathrm{~mm}$ AAC blocks were weighted by balance. Volume of the blocks were determined. By dividing the weight with the volume of sample, the unit weight of AAC would be calculated. Same procedure was applied for conventional blocks.

\subsubsection{Mechanical properties}

Compressive strength test of the three AAC blocks were determined by compressive strength testing machine according to ASTM C109 standard. This test was performed after 7days from casting of blocks. Tensile strength of 7days was tested for three AAC briquettes by tensile strength testing machine according to ASTM C307.

Compressive and tensile strength of controlled blocks and briquettes were determined in the same procedure stated above and the result of AAC samples were compared with that of conventional concrete.

\subsubsection{Functional properties}

\subsubsection{Water absorption test}

Water absorption capacity of AAC blocks were determined according to BS 1881-122 standard. Three AAC blocks after 7 days from its casting were kept in the electric oven at $105^{\circ} \mathrm{C}$ for $72 \mathrm{~h}$. These blocks were far at distance $25 \mathrm{~mm}$ from each other. After that, the AAC blocks were dispelled from the oven and block samples were gentled in the airtight pot for $24 \pm 0.5 \mathrm{~h}$. Then each block was weighed by a balance and all the blocks were immersed in a bowl with water depth $25 \pm 5 \mathrm{~mm}$ from the upper surface of sample blocks. After the time of $30 \pm 0.5 \mathrm{~min}$ the blocks were taken from the bowl. Each block was dried with cloth very quickly after taking from bowl with water. Then each block was weighed by the balance. The increased of weight as the percentage of its full dry weight and by which water absorption capacity of AAC blocks were calculated.

\subsubsection{Surface absorption test}

Surface absorption test or capillary test of AAC blocks were determined according to (Ioannou et al., 2008). After 7days from casting of AAC blocks, these blocks were sealed with wax except one surface which would be contacted to water. Sealed blocks were weighed by balance and they were kept in a narrow tray with water of $5 \mathrm{~mm}$ depth. Weight of each block was weighed at consistent interval of $12 \mathrm{~h}$ for the total time $60 \mathrm{~h}$.

\section{RESULTS AND DISCUSSIONS}

There were six sets of AAC sample with two different amount of aluminium $(0.4 \%$ and $0.8 \%$ of weight of OPC) and three high temperatures $\left(160^{\circ} \mathrm{C}, 180^{\circ} \mathrm{C}\right.$ and $\left.200^{\circ} \mathrm{C}\right)$. 


\subsection{Unit weight of AAC and control block}

Unit weight is the physical property of a concrete block both for AAC and normal block. Unit weight of concrete varies with the different cement, various material characteristics of sand, amount of entrained air etc. Figure-1 shows the variation of unit weight with different amount of aluminium and autoclaving temperature.

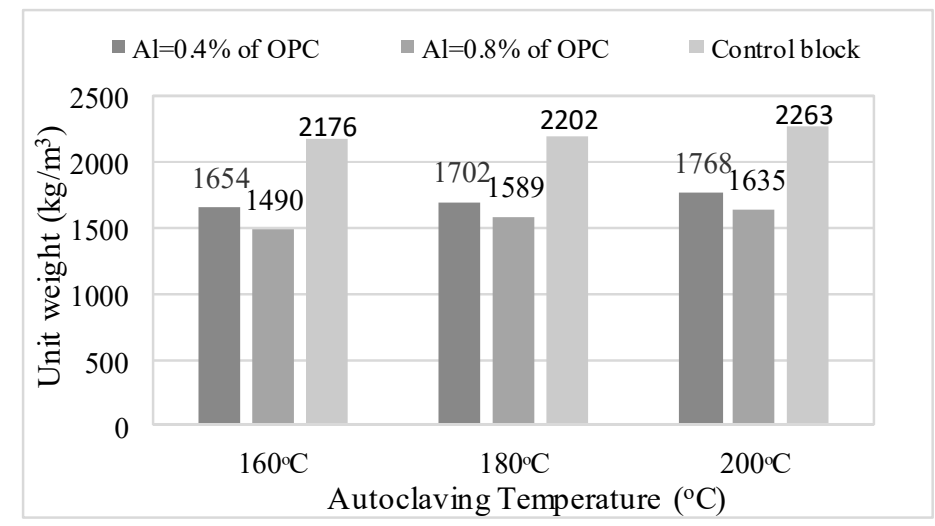

Figure 1: Variation of unit weight of AAC and control block

From Figure 1 it is seen that, unit weight of AAC blocks increases with decreasing aluminium content and increasing autoclaving temperature. The AAC sample with aluminium content $0.8 \%$ of $\mathrm{OPC}$ and $160^{\circ} \mathrm{C}$ autoclaving temperature shows lowest unit weight $\left(1490 \mathrm{~kg} / \mathrm{m}^{3}\right)$. Again, unit weight of AAC is less than control blocks (normal weight concrete). Aluminium powder is used as a foaming agent. Aluminium powder reacts with $\mathrm{Ca}(\mathrm{OH})_{2}$ and after reaction hydrogen gas $\left(\mathrm{H}_{2}\right)$ is produced that makes concrete porous. So, if aluminium content is increased, more porosity will be produced in the concrete and it becomes more light weight. Unit weight of $\mathrm{AAC}$ and controlled block is lower at autoclaving temperature of $160^{\circ} \mathrm{C}$ due to the change of chemical composition. From Figure-1, the highest weight reduction of AAC with respect to control block was $31.53 \%$. Dry density or unit weight of aerated concrete decreases with aluminium content (Kumar and Ramamurthy, 2015). The experimental result follows the trend from previous research works.

\subsection{Strength of AAC and control block}

The strength of AAC is less than that of control concrete. The compressive and tensile strength both for autoclaved aerated concrete and conventional or normal weight concrete were determined to compare the results between this two.

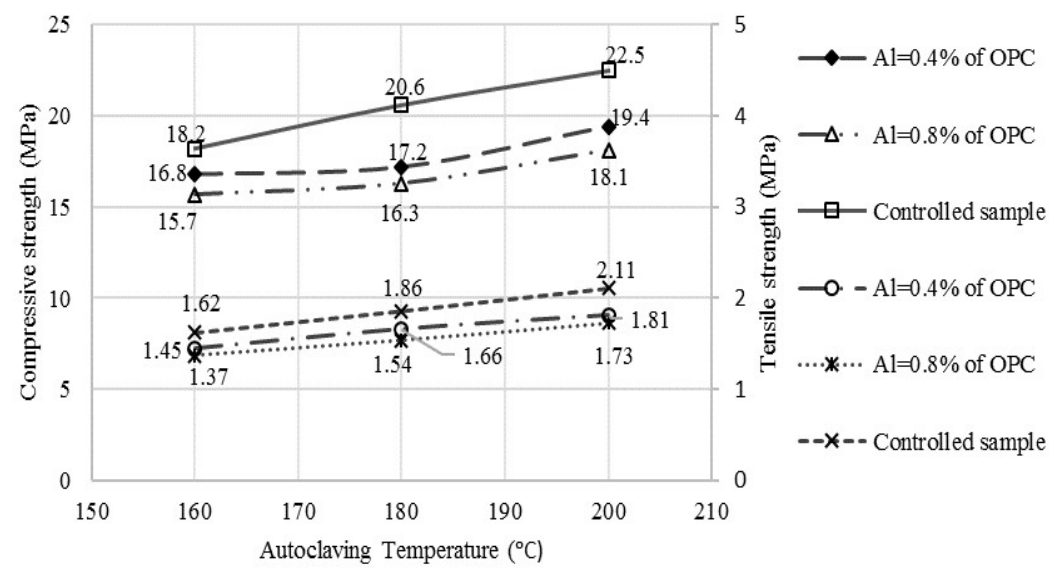

Figure 2: Variation of strength of AAC and control block

From Figure 2, strength of autoclaved aerated concrete increases with decreasing aluminium content and increasing autoclaving temperature. For controlled block, this strength increases with autoclaving temperature. There is little difference of strength between AAC and controlled sample. Strength of controlled sample is 
higher than AAC because of its porosity and less unit weight with respect to normal weight (controlled sample). The maximum compressive and tensile strength of normal weight concrete are $22.5 \mathrm{MPa}$ and $2.11 \mathrm{MPa}$ respectively and for AAC they are $19.4 \mathrm{MPa}$ and $1.81 \mathrm{MPa}$ respectively at aluminium $=0.4 \%$ of $\mathrm{OPC}$ and $200^{\circ} \mathrm{C}$ autoclaving temperature. The lowest strength is seen at aluminium $=0.8 \%$ of $\mathrm{OPC}$ and $160^{\circ} \mathrm{C}$ among all the criterions in this research work. Because of lower unit weight, concrete has lower strength. At lower temperature and higher aluminium content unit weight of AAC was less.

The strength of aerated concrete varies linearly with density of that type of concrete (Mirza \& Ai-noury, 1986).Strength of AAC increases with autoclaving temperature at high pressure (Shabbar et al., 2016). The experimental result follows the trend of previous works.

\subsection{Water and surface absorption of AAC and control block}

The capacity of water absorption of concrete is functional property of concrete. The capacity of water absorption of concrete is presented as the percentage of the fully dried weight of concrete.

The capacity of water absorption of autoclaved aerated concrete generally lies in the range of greater than $8 \%$ to $11.1 \%$ of its dry unit weight (Shabbar et al., 2018). Water absorption capacity of AAC depends on autoclaving temperature, pressure, aluminium content, unit weight of AAC etc. Concrete is more durable when water absorption capacity is less.
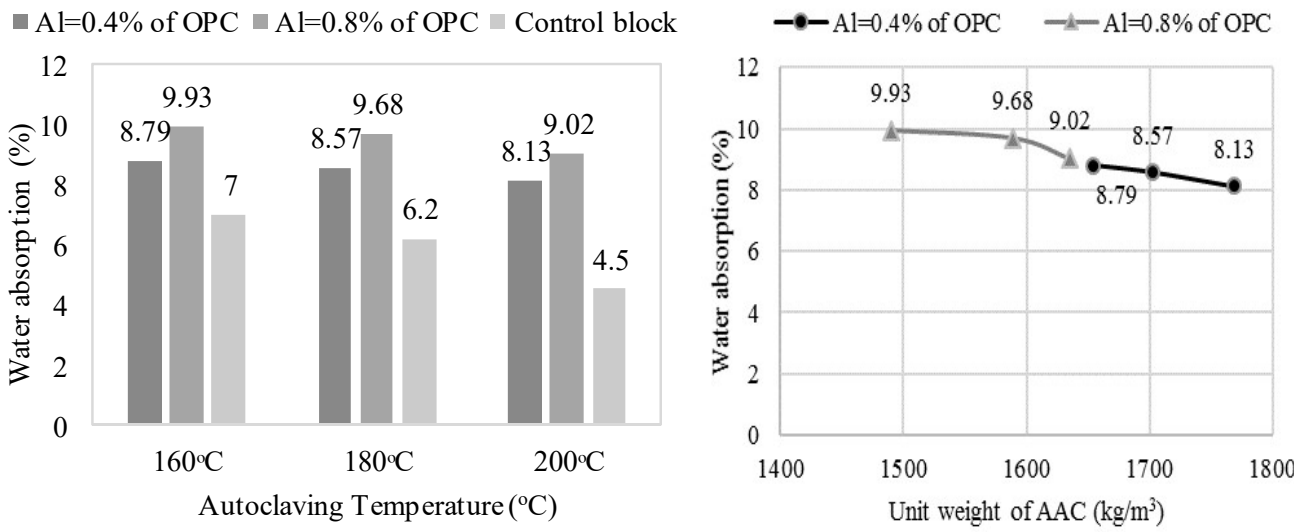

Figure 3: Water absorption of AAC and control block. Figure 4: Change of water absorption with unit weight.

From Figure 3, water absorption capacity of autoclaved aerated concrete increases with aluminium content and this capacity both for AAC and controlled block decreases with autoclaving temperature. Capacity of water absorption of AAC is higher than that of controlled block because of porosity properties of AAC. When aluminium content is higher, more $\mathrm{H}_{2}$ gas is produced and more pore will be created. At higher autoclaving temperature $\left(200^{\circ} \mathrm{C}\right)$ and pressure $(8 \mathrm{~atm})$, samples gave higher unit weight. From Figure 4, water absorption capacity of AAC decreases almost linearly with unit weight of AAC. Number of pores of sample reduces with unit weight and that's why water absorption capacity is reduced with unit weight.

Aerated concrete (foamed concrete) with less dry density or unit weight absorbs more water and these type of samples are less durable for structural work (Kearsley \& Wainwright, 2017). So, the above results obey the previous research work.

Surface absorption test of concrete also known as the capillary test of concrete. In the surface absorption test, wax was used as the sealing agent. The amount of surface absorption of concrete block will be decreased with time. Initially the surface absorption rate is high. With the time this rate will be decreased. 


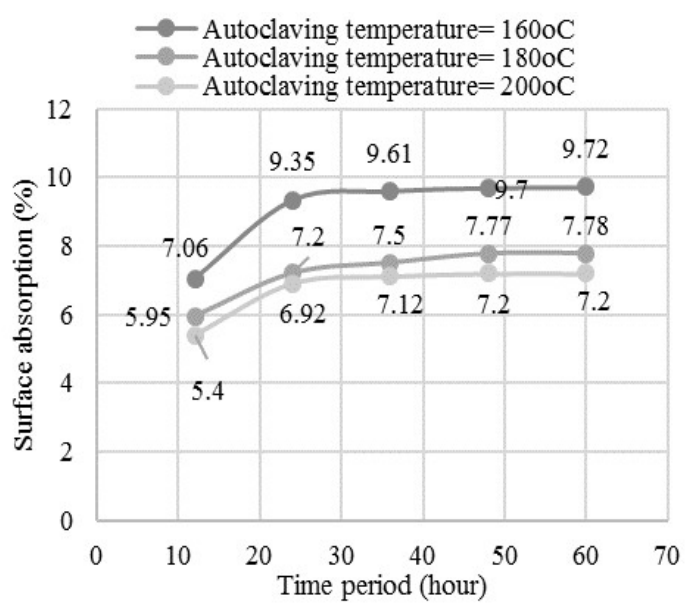

Figure 5: Changing of surface absorption with time for aluminium $=0.4 \%$ of $\mathrm{OPC}$

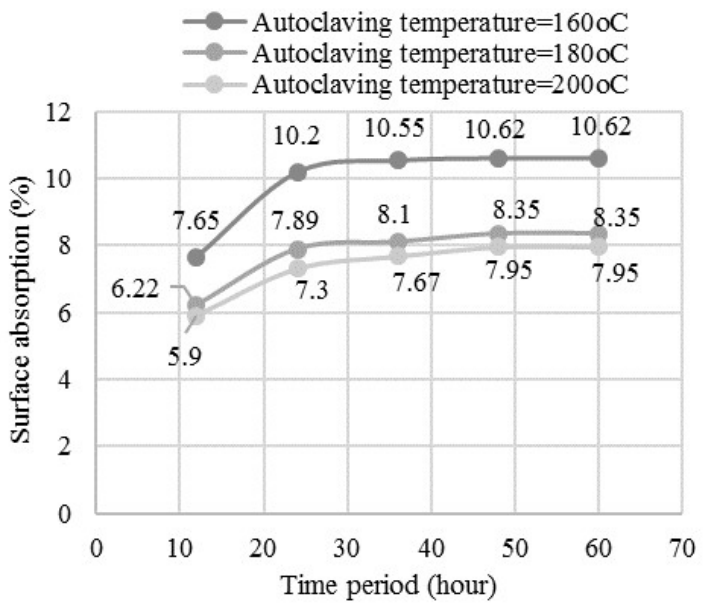

Figure 6: Changing of surface absorption with time for aluminium $=0.8 \%$ of OPC

From Figure 5 and Figure 6, surface absorption capacity of AAC blocks decreases with autoclaving temperature. This is happened for the same reason stated above for water absorption capacity of AAC. At initial time absorption rate is higher, so the slope of the graph is steeper for $1^{\text {st }} 12$ hours. At that time there are small pores and these are filled with water quickly. After 12 hours, the block is getting its saturation position and absorption rate is decreased and after 60 hours' rate is almost constant and graph is linear. Then no amount of water is absorbed by the capillary action.

Surface absorption capacity of aerated concrete increases with aluminium content and initially absorption rate is high and at the final time rate will be constant (Shabbar et al., 2018). So, the experimental result follows the trend of previous research work.

\section{CONCLUSIONS}

The physical, mechanical and functional properties of AAC were determined with two aluminium content and three high autoclaving temperature in this research work. These properties were compared with that of control concrete. These properties vary with different aluminium content and autoclaving temperature. Unit weight of $\mathrm{AAC}$ was less than conventional concrete. Unit weight of AAC decreases with aluminium content and with decreasing autoclaving temperature. The more light- weight AAC sample was one with $0.8 \%$ aluminium of OPC and $160^{\circ} \mathrm{C}$ autoclaving temperature and unit weight was $1490 \mathrm{~kg} / \mathrm{m}^{3}$ and here the weight reduction of that AAC sample was $31.53 \%$ with respect to conventional concrete.

The strength (compressive and tensile) of AAC of 7days was almost near to that of conventional concrete block. Strength of AAC decreases with aluminium content and strength increases with autoclaving temperature. Maximum compressive and tensile strength for AAC with $0.4 \%$ aluminium and $200^{\circ} \mathrm{C}$ autoclaving temperature were $19.4 \mathrm{MPa}$ and $1.81 \mathrm{MPa}$ respectively whereas for conventional concrete block, they were $22.5 \mathrm{MPa}$ and $2.11 \mathrm{MPa}$ respectively at same autoclaving temperature.

Water and surface absorption capacity of AAC as its functional properties increases with aluminium content and decreases with temperature. Maximum water absorption capacity of AAC with $0.8 \%$ aluminium content and $160^{\circ} \mathrm{C}$ autoclaving temperature was $9.93 \%$. Capacity of water absorption of AAC was much greater than that of control block because of porosity. Water absorption capacity was almost linearly decreased with unit weight of AAC.

Surface absorption rate of AAC was higher at initial time. For $1^{\text {st }} 12$ hours block absorbed more water by capillary action. After 60 hours, this rate was almost constant due to its saturated condition.

\section{ACKNOWLEDGEMENTS}

The author would like to thank the Strength of Materials and Concrete laboratory, Department of Civil Engineering, Khulna University of Engineering \& Technology, Khulna, Bangladesh for providing laboratory services and the laboratory technicians of this laboratory for their helping hand to fulfil this work. This is to declare that a part of this paper has been presented in ICCESD 2020 conference. 


\section{REFERENCES}

Neville, A. M. 2011. Properties of Concrete, 5th Edition, Pearson Education Limited, Edinburgh Gate, Harlow Essex CM20 2JE, England.

Anon., 1970. Guide for Structural Lightweight Aggregate Concrete, ACI Committee Report 213, American Concrete Institute.

ASTM C109 / C109M-20b, 2020. Standard Test Method for Compressive Strength of Hydraulic Cement Mortars (Using 2-in. or [50 mm] Cube Specimens), ASTM International, West Conshohocken, PA.

ASTM C307-18, 2018. Standard Test Method for Tensile Strength of Chemical-Resistant Mortar, Grouts, and Monolithic Surfacings, ASTM International, West Conshohocken, PA.

BS 1881-122., 1983. British Standard, Method for determination of water absorption. lbocvzr lbocvzr, University of Loughborough, 1-4.

Hauser, A., Eggenberger, U., \& Mumenthaler, T., 1999. Fly ash from cellulose industry as secondary raw material in autoclaved aerated concrete, Cement and Concrete Research, 29, 297-302.

Holt, E., \& Raivio, P., 2005. Use of gasification residues in aerated autoclaved concrete, Cement and Concrete Research, 35, 796- 802

Ioannou, I., Hamilton, A., \& Hall, C., 2008. Capillary absorption of water and $\mathrm{n}$-decane by autoclaved aerated concrete, Cement and Concrete Research, 38, 766-771

Kearsley, E. P., \& Wainwright, P. J., 2017. Porosity and permeability of foamed concrete, Cement and Concrete Research, 31, 805-812

Koronthalyova, O., 2011. Moisture storage capacity and microstructure of ceramic brick and autoclaved aerated concrete, Construction and Building Materials, 25(2), 879-885.

Kumar, E. M., \& Ramamurthy, K., 2015. Effect of fineness and dosage of aluminium powder on the properties of moist-cured aerated concrete, Construction \& Building Materials, 95, 486-496.

Mirza, W. H., \& Ai-noury, S. I., 1986. Utilisation of Saudi sands for aerated concrete production, The international Journat of Cement Composites and Lightweight Concrete, 8(2), 81-85.

Narayanan, N., \& Ramamurthy, K., 2000. Structure and properties of aerated concrete : a review, Cement \& Concrete Composites, 22, 321-329.

Robert, C., Jerman, M., Keppert, M., \& Vy, J., 2013. Hygric , thermal and durability properties of autoclaved aerated concrete, Construction and Building Materials, 41, 352-359

Sanjayan, J. G., Nazari, A., Chen, L., \& Nguyen, G. H., 2015. Physical and mechanical properties of lightweight aerated geopolymer, Construction \& Building Materials, 79, 236-244.

Shabbar, R., Nedwell, P., \& Wu, Z., 2016. Influence of temperature and curing method on strength of autoclaved aerated concrete, Proceeding of the MACE PGR Conference 2016, 9-11.

Shabbar, R., Nedwell, P., \& Wu, Z., 2018. Porosity and Water Absorption of Aerated Concrete with Varying Aluminium Powder Content, International Journal of Engineering and Technology, 10(3), 234-238.

Tanaçan, L., Ersoy, H. Y., \& Arpac, Ü., 2005. Effect of High Temperature on the Mechanical Properties and Ultrasound Velocity of Cellular Gas Concrete, 10DBMC International Conférence On Durability of Building Materials and Components, 17-20 April, 2005.

Tanaçan, L., Yas, H., \& Arpaciog, Ü., 2009. Effect of high temperature and cooling conditions on aerated concrete properties, 10DBMC International Conférence On Durability of Building Materials and Components, 17-20 April, 2005, 1240-1248.

Un, H., \& Baradan, B. (2011). The effect of curing temperature and relative humidity on the strength development of Portland cement mortar. Scientific Research and Essays, 6(12).

Wakili, K. G., Hugi, E., Karvonen, L., Schnewlin, P., \& Winnefeld, F., 2015. Cement \& Concrete Composites Thermal behaviour of autoclaved aerated concrete exposed to fire, Cement and Concrete Composites, 62, $52-58$.

(C) 2021 the JES. Journal of Engineering Science published by Faculty of Civil Engineering, Khulna University of Engineering \& Technology. This is an open access article under the terms of the Creative Commons AttributionNonCommercial-NoDerivatives License, which permits use and distribution in any medium, provided the original work is properly cited, the use is non-commercial and no Modifications or adaptations are made. 